Cell Research(1993),3, 147-156

\title{
Effect of antikeratin microinjection on the embryonic development of Xenopus laeyis
}

\author{
YU HaOjian, Jingwu XIE, Feng CAO, JinhuA \\ LIANG \\ Department of Biology, Beijing University, Beijing \\ 100871, China
}

\begin{abstract}
Anti-keratin monoclonal antibody AF5 was introduced into fertilized eggs of Xenopus laevis., and its effects on embryonic development were studied. Survival rate of the antikeratin-injected embryos was much lower (only $35.76 \%$ at gastrula) than that of the control $(74.85 \%$ at gastrula), in which embryos were injected with mouse IgG. Most of survivors in the experimental series showed aberrant external appearance. On the other hand, in cleavage stage, ie 2-7 $\mathrm{h}$ after fertilization, immunohistochemical staining of embryos showed that the experimental embryos were mostly keratin negative, while embryos of the control ones were keratin positive. When introducing this antikeratin into one cell of a 2-cell embryo, only the uninjected half of the embryo continued its development while the other half could not develop at all. These results suggested that intact keratin cytoskeleton in early embryos is indispensable to the embryonic development of Xenopus laevis.
\end{abstract}

Key words: Xenopus laevis, fertilized egg, keratin, cytoskeleton, monoclonal antibody, microinjection.

\section{INTRODUCTION}

Keratins are members of intermediate filaments which together with microfilaments and microtubules make up the cytoskeleton in epithelial cells. The expression patterns of keratin are tissue-specific and are regulated developmentally[1]. Keratins are also present in some plant cells, certain invertebrate and most vertebrate em- 
bryonic cells[2,3,4]. At present, the function of keratins remains obscure. Keratins in cultured cell have been described as a skeletal structure based largely on their stability under physiological conditions and on their organization in the cell. Since no specific inhibitors for keratins have been detected, antikeratins are being used to study the function of keratins. It has been revealed that microinjection of one kind of antikeratin into cultured epithelial ptK1 cells resulted in disruption of all keratin fibrils of the cell, forming a crescent structure around the nucleus. Keratin cytoskeleton reappeared 20-24 h after microinjection. But introducing antikeratins into cultured cells did not affect cell growth and cell division[5,6]. After microinjection of epidermal keratins mRNA into non-epithelial cells containing only vimentin filaments, keratin polypeptides were synthesized and assembled into intermediatesized filaments at multiple dispersed sites in the recipient cells. The presence of extended keratin fibril meshworks in these injected cells was compatible with cell growth and mitosis[7]. 3T3 fibroblast cells could be forced to express human keratins without change in cell physiology and cell morphology[8]. Thus, it seemed that keratin did not diplay important functions in these cultured cell lines.

Previous works[5,6] indicated that microinjection of monoclonal antibody $(\mathrm{MAb})$ was a useful technique to analyze the composition, and the putative function of keratin filaments. After microinjection, the antibody may coat these filaments or disrupt their integrity, thereby blocking their functions. Emerson introduced antikeratin into preimplantational mouse embryo by microinjection[9]. The disruption of keratin cytoskeleton in early mouse embryo was transient and did not disturb the formation of the blastocyst. An extensive keratin network emerged in later blastocyts stage of injected embryos, despite the initial disruption of cytokeratin assembly. Since embryonic development of mouse is much slower than that of Xenopus laevis, mouse embryo could still undergo cell division after antikeratin injection and other developmental stages of mouse could follow after keratin cytoskeleton reappeared. These results did not rule out the importance of keratin during embryonic development. In fact, mouse embryo may not be an appropriate experimental model for the study of keratin functions during early embryonic development. In contrast, the development of Xenopus laevis is rapid enough for us to observe the effects of antikeratin on embryonic development. At room temperature, the fertilized egg of Xenopus laevis has already developed into a 256-celled blastula within $12 \mathrm{~h}$, whereas mouse embryo is still in the first cell division during the same period. We therefore chose Xenopus laevis embryo to investigate the importance of keratin cytoskeleton for early embryonic development. In this paper, the effects of antikeratin MAb AF5 [10] on the embryonic development after its microinjection into the fertilized eggs and 2-cell stage embryos of Xenopus laevis will be presented.

\section{MATERIALS AND METHODS}

\section{Anirnal}


Xenopus laevis in this study was raised in our laboratory. Spawning was induced by injection of gonadotropic hormone into the dorsal lymph sac. The dosage used was 100 I.U. in the first injection for both the males and females. The second injection, with a dosage of 300 I.U. for the females and $100 \mathrm{I}$.U. for the males was carried out $8 \mathrm{~h}$ after the first. Females began to lay eggs 8-12 $\mathrm{h}$ after the second injection. All the embryos in this study were raised at $20^{\circ} \mathrm{C}$ under the same condition.

Developmental stages were identified according to Nieuwkoop and Faber[11].

\section{Antibodies}

A mouse antikeratin monoclonal antibody AF5 was used in this study which was provided by the Pathology Lab of Chongqing Medical University. Immunohistochemical study showed that AF5 stained specifically cells superficial to the basal layer in human epithelium[10]. Xenopus fertilized eggs and early embryos could also be stained by AF5 antikeratin antibody (unpublished results in our lab). Three polypeptides of keratins $(60,65$ and $68 \mathrm{Kd})$ in oocytes, fertilized eggs of Bufo bufo gargarizans were recognized by this antibody[12]. In order to exclude the possibility that antibody IgG itself might affect embryonic development, normal mouse IgG was injected into Xenopus eggs (National Vaccine and Serum Institute, Beijing) to serve as the control.

\section{Microinjection}

In this study, experiments of fertilized eggs and 2-cell embryos were divided into 4 groups (Tab 1): Group A-the experiments series, each egg was injected with $50 \mathrm{nl}$ of AF5 IgG (about $300 \mathrm{ng}$ of IgG at a concentration of $6 \mathrm{mg} / \mathrm{ml}$ ) according to procedures described in previous works $[1,13]$. Group B-the control series, each egg was injected with $50 \mathrm{nl}$ of mouse IgG at the same concentration as in Group A. Group C-the experimental series, a 2-celled embryo was injected with $25 \mathrm{nl}$ of AF5 IgG into either one of the two cells only. Group D-the control series, a 2-celled embryo was injected with $25 \mathrm{nl}$ of mouse IgG into any one cell only.

The injected cells in Group C and D were abbreviated as IC, the uninjected ones as UC.

\section{Enzyme immunohistochemistry}

Two and $7 \mathrm{~h}$ after fertilization, 10 embryos per group of A and B were separately fixed, sectioned and stained using the method of Gall et al[14]. Antikeratin AF5 served as the first antibody, and goat anti-mouse IgG as the second. Peroxidase anti-peroxidase complex(PAP, from National Vaccine and Serum Institute, Beijing), 3,3-diaminobenzidine hydrochloride (DAB, from Sigma) and $\mathrm{H}_{2} \mathrm{O}_{2}$ were used as substrates. Then the slides were stained by hematoxylin for 1-2 s. Keratin positive areas stained brown, while keratin negative areas light blue.

\section{RESULTS}

\section{Microinjection of AF5 MAb into fertilized eggs}

Survival rate and embryonic morphology were scrutinized in the development of the injected eggs.

The survival rate in the experimental series at gastrula was only about $35.76 \%$, while that of the control was about $74.85 \%$ (Tab 1). At St.45 tadpole, the survival rate in experimental series $(5.45 \%)$ was only about a quarter of that the control $(21.6 \%)$ (Tab 1).

The differences of embryonic morphology between the experimental series and the control were observed in certain important stages.

(1) Cleavage stage

About 90 min after fertilization, fertilized eggs began to divide. In the experi- 
Effect of antikeratin on the embryonic development of Xenopus laevis

mental series, eggs were either abnomally divided (Fig 2), or even did not divide at all. In contrast, most of cleavages in the control were normal (Fig 1).

Tab 1. Embryonic development of Xenopus laevis after microinjection of antikeratin antibodies

\begin{tabular}{|c|c|c|c|c|c|c|c|}
\hline & & Eggs & Gastrula & Tailbud & St.32 & St.35 & St.45 \\
\hline $\begin{array}{l}\text { Time after } \\
\text { fertilization }\end{array}$ & & $\begin{array}{c}0.5 \mathrm{~h} \\
\text { or } 1.5 \mathrm{~h}\end{array}$ & $16 \mathrm{~h}$ & $30 \mathrm{~h}$ & $40 \mathrm{~h}$ & $48 \mathrm{~h}$ & $72 \mathrm{~h}$ \\
\hline \multirow{2}{*}{$\begin{array}{l}\text { Injection } \\
\text { into } \\
\text { fertilized } \\
\text { eggs }\end{array}$} & $\begin{array}{c}\text { Group* } \\
\text { A }\end{array}$ & $\begin{array}{l}165 \\
(100 \%)_{* *}\end{array}$ & $\begin{array}{c}59 \\
(35.76) \%\end{array}$ & $\begin{array}{c}29 \\
(17.58 \%)\end{array}$ & $\begin{array}{c}15 \\
(9.09 \%)\end{array}$ & $\begin{array}{c}12 \\
(7.27 \%)\end{array}$ & $\begin{array}{c}9 \\
(5.45 \%)\end{array}$ \\
\hline & $\begin{array}{c}\text { Group } \\
\text { B }\end{array}$ & $\begin{array}{c}338 \\
(100 \%) \\
\end{array}$ & $\begin{array}{c}253 \\
(74.85 \%) \\
\end{array}$ & $\begin{array}{c}158 \\
(46.75 \%) \\
\end{array}$ & $\begin{array}{c}132 \\
(39.75 \%) \\
\end{array}$ & $\begin{array}{c}90 \\
(26.63 \%) \\
\end{array}$ & $\begin{array}{c}73 \\
(21.60 \%) \\
\end{array}$ \\
\hline $\begin{array}{l}\text { Injection } \\
\text { into one } \\
\text { cell at }\end{array}$ & $\begin{array}{c}\text { Group } \\
\text { C }\end{array}$ & $\begin{array}{c}63 \\
(100 \%)\end{array}$ & $\begin{array}{c}31 \\
(49.21 \%)\end{array}$ & $\begin{array}{c}16 \\
(25.40 \%)\end{array}$ & $\begin{array}{c}12 \\
(19.05 \%)\end{array}$ & $\begin{array}{c}12 \\
(19.05 \%)\end{array}$ & $\begin{array}{c}12 \\
(19.05 \%)\end{array}$ \\
\hline $\begin{array}{l}\text { 2-cell stage } \\
\text { embryo }\end{array}$ & $\begin{array}{c}\text { Group } \\
\text { D }\end{array}$ & $\begin{array}{c}76 \\
(100 \%)\end{array}$ & $\begin{array}{c}50 \\
(65.79 \%)\end{array}$ & $\begin{array}{c}37 \\
(48.68 \%)\end{array}$ & $\begin{array}{c}32 \\
(42.11 \%)\end{array}$ & $\begin{array}{c}31 \\
(40.79 \%)\end{array}$ & $\begin{array}{c}28 \\
(36.84 \%)\end{array}$ \\
\hline
\end{tabular}

* Group A-Each egg was injected with $50 \mathrm{nl}$ of AF5 IgG.

Group C-2 cell stage embryo was injected with $25 \mathrm{nl}$ of AF5 IgG in one cell only.

Group B and D-the control series, injected with the same amount of mouse IgG as group A and C.

Embryos used for fixation and section were not included.

$* *(\%)$ indicates survival rate.

(2) Gastrula

The protrustive yolk plug in the experimental series (Fig 4) indicated that the ingression of the yolk plug was impeded, while gastrulation in the majority of the control embryos went on quite well (Fig 3).

(3) St. 45

All the survivors in the control appeared externally normal (Fig 5). In contrast, embryos of the experimental series were aberrant. They were of different types: some of them developed slowly (Fig 6); some had swollen abdomens with many vesicles around their bodies (Fig 7); while others had curved spines and poorly developed heads (Fig 8).

In addition, enzyme immunohistochemistry of the emberyos were done in $10 \mathrm{em}$ bryos per group of A and B at 2 celled stage ( $2 \mathrm{~h}$ after fertilization) and midcleavage stage ( $7 \mathrm{~h}$ after fertilization). The results showed that of the 10 antikeratin-injected embryos, 6 were keratin negative and 4 weakly stained, implying that keratin cytoskeleton was destroyed after antikeratin microinjection. In contrast, 10 embryos in the control were keratin positive, indicating that antibody IgG itself did not affect keratin during Xenopus embryonic development. All positive reactions were stained brown in color (data not shown).

\section{Microinjection of antibodies into 2-cell stage embryos}

In order to get more evidence of the importance of keratin cytoskeleton in early embryos, we introduced AF5 IgG into one cell of a 2-cell stage embryo (Group C). 
At the same time, normal mouse IgG injected control group was also carried out (Group D).

The survival rate and embryonic morphology were scrutinized in these groups. For the survival rate, only 16 out of 63 (25.40\%) embryos developed into the tailbud stage in experimental series (Tab 1), of which 12 (19.05\%) developed into St.45 tadpoles while others died before St.32. As to the control, 37 out of 76 (48.68\%) embryos developed into tailbud embryos, of which 28 (36.84\%) developed into St.45 tadpoles. The survival rate in control series was almost twice that of the experimental series.

The difference in embryonic morphology between the experimental series and the control was observed during the following stages:

(1) Cleavage stage

In the 2-cell stage embryo of the experimental series (Group C), the uninjected cell (UC) continued its successive cleavage, while the injected cell (IC) remained undivided (Fig 9, 10). In the controls (Group D), both IC and UC carried on their cleavage as usual.

(2) Blastula

In the experimental series, the UC area developed into blastula in which many small-sized cells were apparently visible, while IC area was occupied only by 2 blastomeres (Fig 11) in most circumstances. Later the IC area became smaller and smaller. The pigment on its animal hemisphere gradually disappeared, while the UC area kept on its normal development.

In addition, histological sections at the cleavage stage and blastula stage were examined. As shown in Fig 12, the UC area of the embryo was divided into many cells while IC area had only 2 cells.

(3) Gastrula

Eventually, the IC area became so small that it became almost invisible. The UC area seemed to develop normally and began its gastrulation with the dorsal lip appeared on its vegetal hemisphere. But at late gastrula stage, 7 out of 31 embryos in the experimental series appeared abnormal because the ingression of their yolk plug was impeded.

(4) Later stages

From gastrula onward, in the expermental series some embryos developed normally, some of them developed in a way something like that of antikeratin-injected fertilized eggs. As shown in Fig 13, some abnormalities with its slightly curved spine were observed.

\section{DISCUSSION}

\section{Effect of antikeratin on the embryonic development}

Results both from the microinjection of normal mouse IgG into either fertilized eggs or 2-cell stage embryos showed that they developed quite normally. It meant that IgG itself did not affect the embryonic development of Xenopus lae- 
Effect of antikeratin on the embryonic development of Xenopus laevis

vis.. In contrast, embryos in the experimental series ceased to develop or developed into aberrant tadpoles after the microinjection of antikeratin AF5 which might coat keratin filaments or disrupt its integrity entirely and block their functions. Both embryonic morphology and survival rate in the experimental embryos were different from those of control embryos. Thus, we concluded that keratin cytoskeleton was very important for the embryonic development of Xenopus laevis. Once the keratin cytoskeleton was damaged or destroyed, the development would be retarded.

\section{Survival rate in the control}

In normal embryonic development of Xenopus laevis, death of embryos was unavoidable due to individual difference in survival ability. Hence, we used more than 100 embryos (or a little less in the case of 2-celled embryos) per group in our microinjection experiments for statistical analysis. From Tab 1, it can be seen that although the difference in survival rate between the experimental series and the control series was easy to tell, the survival rates of the control groups B and D were not as high as what we would have expected. This might be due to:

(1) The survival rate was certainly less than $100 \%$ even if under normal developmental conditions without any microinjection.

2) The process of rolling off the jelly from fertilized eggs before microinjection often affected its later development, because in this process the gray crescent areas of some eggs, which were important to the development, may become damaged to some extent.

(3). Microinjection itself may also caused some mild or minor injuries to some embryos since a little bit of cytoplasm usually flowed out from these embryos.

\section{Dosage of antikeratin needed to disrupt keratin cytoskeleton}

As no data were available for the dosage of antikeratin in microinjection experiments with Xenopus embryo, we chose our injection dosage according to previous works in cultured cells. It was shown by other workers that high concentration (6-7 $\mathrm{mg} / \mathrm{ml}$ ) of antibody solution was required to disrupt, collapse or aggregate the intermediate filaments[1,5,6]; the proportion of injected MAb IgG to keratin molecules of the recipient cell was 1:10. In our study, $300 \mathrm{ng}$ AF5 IgG (50 nl) was introduced into each fertilized egg. There was about $5 \mu \mathrm{g}$ of keratins in one fertilized egg (our unpublished data). From the molecular weight of both IgG and keratins, the molecular ratio of IgG to keratin in the injected egg was about 1:8, a value close to previously used dosage in cultured cells. In order to allow normal development of Xenopus embryos, the maximum tolerable amount of solution injected should be 50 $\mathrm{nl}[13]$. So this dosage of antikeratin should be sufficient to disrupt keratin filaments in the Xenopus early embryonic cells.

\section{Possible functions of keratincytoskeleton in early embryos}


Previous results in cultured cells[5,15] showed that keratin cytoskeleton in the cell could be recovered 20-24 h after its disruption by antikeratin. As to Xenopus, the time needed for keratin cytoskeleton to reappear was not precisely known in our study. At least we can conclude that it was no less than $7 \mathrm{~h}$ because immunohistochemical staining still showed negative results $7 \mathrm{~h}$ after microinjection of antikeratin i.e. in the mid-cleavage stage. So we suggested that keratin cytoskeleton played an important role, possibly in cell cleavage. Our results revealed that when introducing antikeratin into fertilized eggs, most abnormal morphology of the embryo became evident from cleavage stage onwards, during which period embryos underwent a series of important events, such as mid-blastula transition, gastrulation, neural tube formation and organ rudiment formation, resulting in abnormal or stagnant embryos. It seems likely that all the abnormalities found during early embryogenesis may, to some extent, a direct consequence of abnormal cleavages.

It was suggested that maternal mRNAs in early embryos were associated with keratin cytoskeleton. Localized maternal RNA Vgl, which coded for a protein involved in dorsal mesoderm induction, was proved to be associated with keratin filaments in Xenopus egg [16]. Gall et al [14] also suggested that the polarity of Xenopus laevis probably involved cytoskeletal structures like the microtubules and intermediate filaments. Goldman [17] proposed that cytoplasmic keratin might be involved in regulating the nuclear-cytoplasm bidirectional flow of information that ultimately may alter genomic and cytoplasmic functions. From our experiments, we have the opinion that keratin cytoskeleton might also play an important role, possibly in mid-blastula transition, mRNA localization and embryonic pattern formation. Further explorations ure still necessary to reveal the actual functions of keratins in early embryogenesis of Xenopus laevis.

\section{ACKNOWLEDGEMENT}

The project was supported by the National Natural Sciences Foundation of China.

\section{REFERENCES}

[1] Shay JW. Cell and Molecular Biology of the Cytoskeleton. Plenun Press, New York. 1986;pp56115.

[2] Ross JHE, Hutchings A, Butcher GW, Lane EB and Lloyd CW. The intermediate filamentrelated system of higher plant cells shares an epitope with cytokeratin 8.J Cell Sci 1991; 99(1):91-8.

[3] Schroeder TE and Otto JJ.Snoods: A periodic network containing cytokeratin in the cortex of starfish oocytes. Dev Biol 1991; 144:240-7.

[4] Markl J. Cytokeratins in mesenchymal cells: impact on functional concepts of the diversity of intermediate filament proteins. J Cell Sci 1991; 99(2):261-4.

[5] Eckert BS, Daley RA and Parysek LM. In vivo disruption of the cytoskeleton in cultured epithelial cells by microinjection of antikeratin: evidence for the presence of an intermediate filamentorganizing center. Cold Spring Harbor Symp Quant Biol 1982; 46:403-12.

[6] Klymkowsky MW, Miller RH and Lane EB. Morphology, behavior and interaction of cultured 


\section{Effect of antikeratin on the embryonic development of Xenopus laevis}

epithelial cells after the antibody induced disruption of keratin filament organization. J Cell Biol 1983; 96:494-509.

[7] Kreis TE, Geiger B, Schmid E, Jorcano JL and Franke WW. De novo synthesis and specific assembly of keratin filaments in nonepithelial cells after microinjection of mRNA for epidermal keratin. Cell 1983; 32:1125-37.

[8] Lu X and Lane EB. Retrovirus mediated transgenic keratin expression in cultured fibroblasts: specific domain functions in keratin protein stabilization and filament formation. Cell 1990; 62:681-96.

[9] Emerson JA. Disruption of the cytokeratin filament network in the preimplantation mouse embryo. Development 1988; 104:219-34.

[10] $\mathrm{Hu} \mathrm{J}$ and Fan W. Characterization of a hybridoma cell line and its antibody specificity. Chinese J Immunol 1987; 3(5):258-62.

[11] Nieuwkoop PD and Faber J. Normal Table of Xenopus laevis. North-Holland Publ. Co., Amsterdam. 1956.

[12] Xie JW and Yu HJ. Keratin expression during early embryonic development of Bufo bufo gargarizans. Cell Res 1992; 2(1):45-52.

[13] Gurdon JB and Wakefield L. Microinjection and organelle transplatation techniques: Methods and applications (Celis JE edited). Academic Press, Jovanvich Publisher. Harcourt Brace. 1986:269-301.

[14] Gall L, Pichearl B and Gounon P. Biochemical evidence for the presence of intermediate filaments and microfilaments in the egg of Xenopus 1aegis. Biol Cell 1983; 47:331-42.

[15] Lane EB and Klymkowsky MW. Epithelial tonofilaments:investigating their form and function using monoclonal antibodies. Cold Spring Harbor Symp Quant Biol 1982; 46:387-402.

[16] Pondel MD and King ML. Localized maternal mRNA related to transforming growth factor RNA is concentrated in a cytokeratin-enriched fraction from Xenopus laevis. Proc Natl Acad Sci USA 1987; 85:7612-6.

[17] Goldman R, Goldman AE, Green KJ, Jones JCR, Jones SM and Yang HY. Intermediate filament networks: organization and possible functions of a diverse group of cytoskeletal elements. J Cell Sci suppl 1986; 5:69-79.

Received 3-7-1992. Revised 7-6-1993. Accepted 8-6-1993.

\section{Plate 1}

In the control, fertilized eggs were injected with normal mouse IgG (Group B), while antikeratin antibody (MAb AF5 IgG) was injected into fertilized eggs in the experimental series (Group A).

Fig 1. 8-celled stage(Group B). $\times 20$

Fig 2. 8-celled stage, abnormal cleavage(Group A). $\times 20$

Fig 3. gastrula stage (Group B). $\times 20$

Fig 4. gastrula stage, protusive yolk plug(Group A). $\times 20$

Fig 5. St.45 tadpole(Group B). $\times 10$

Fig 6. Development-retarded tadpole(Group A). $\times 10$

Fig 7. Tadpole with swollen abdomen and vesicles (Group A). $\times 10$

Fig 8. Seriously abnormal tadpole with poorly developed head(Group A). $\times 10$ 
Yu HJ et al.
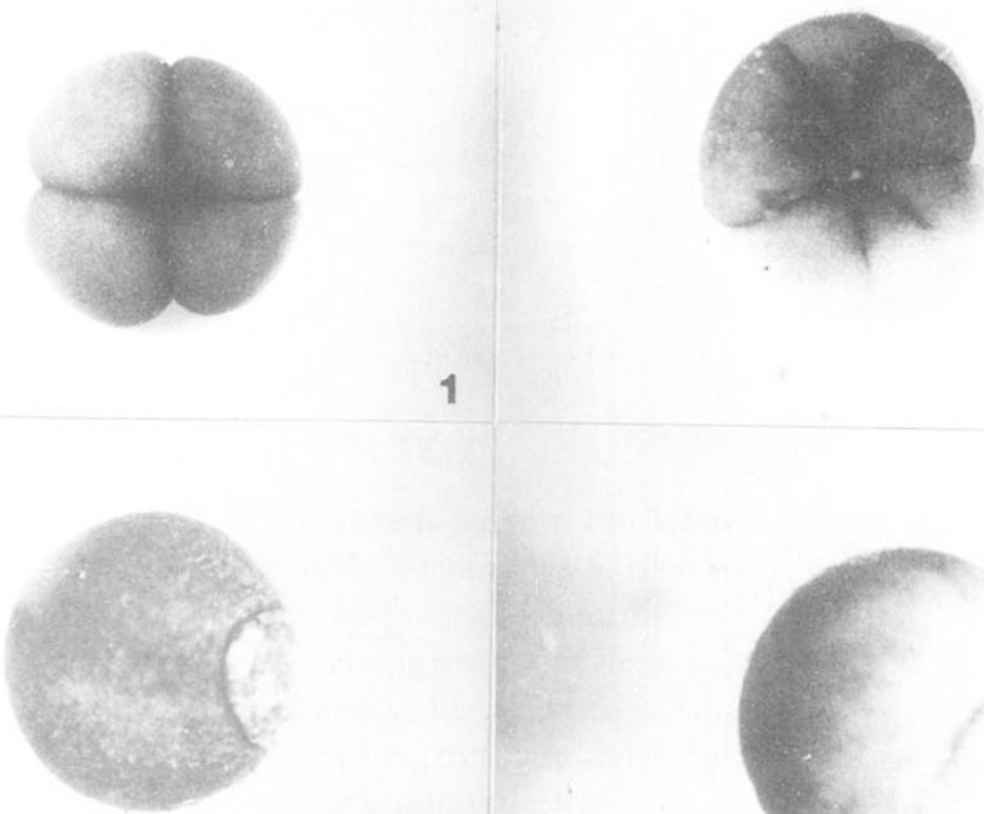

3

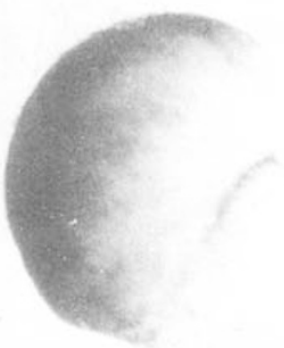

4
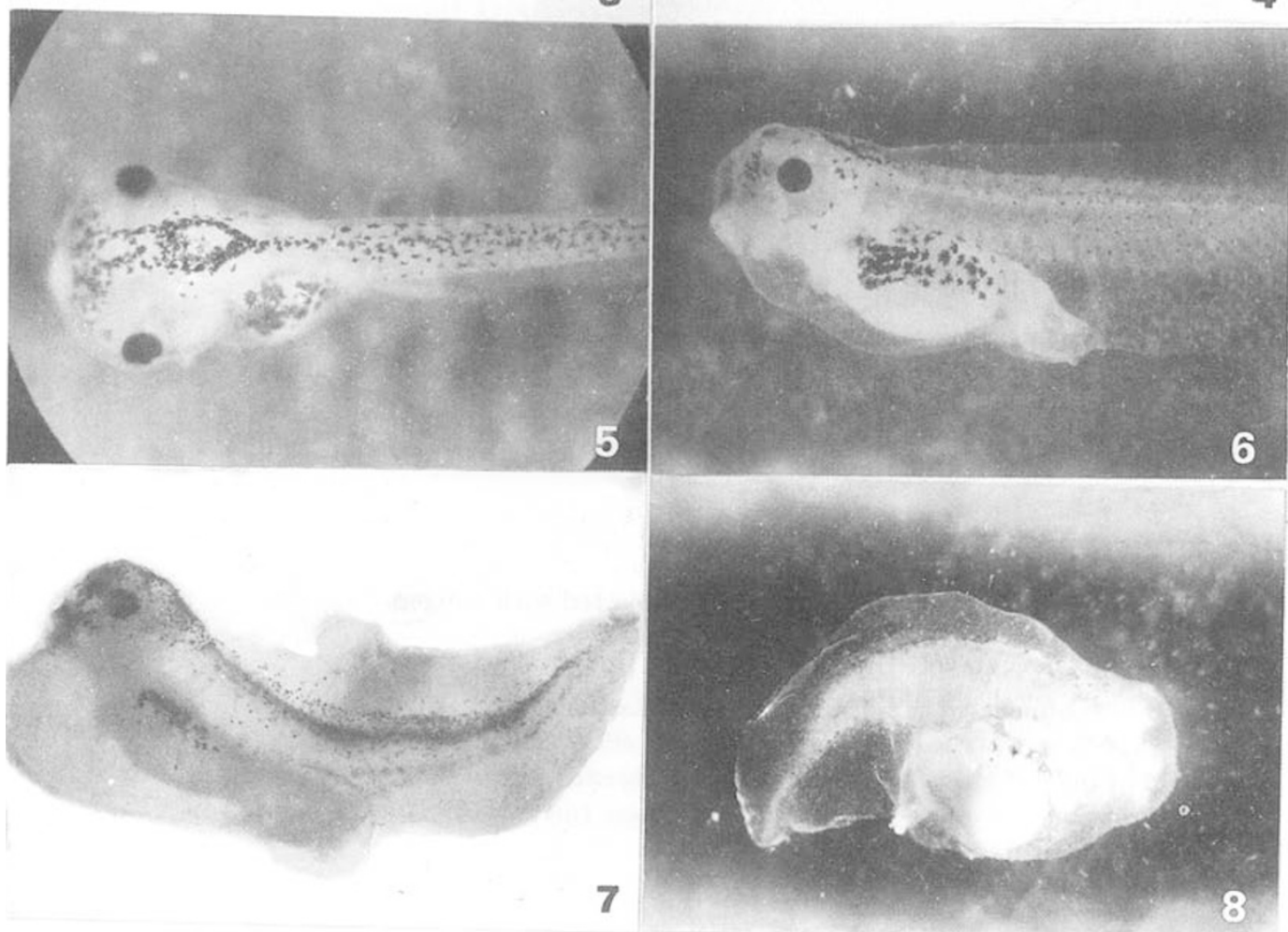
Effect of antikeratin on the embryonic development of Xenopus laevis

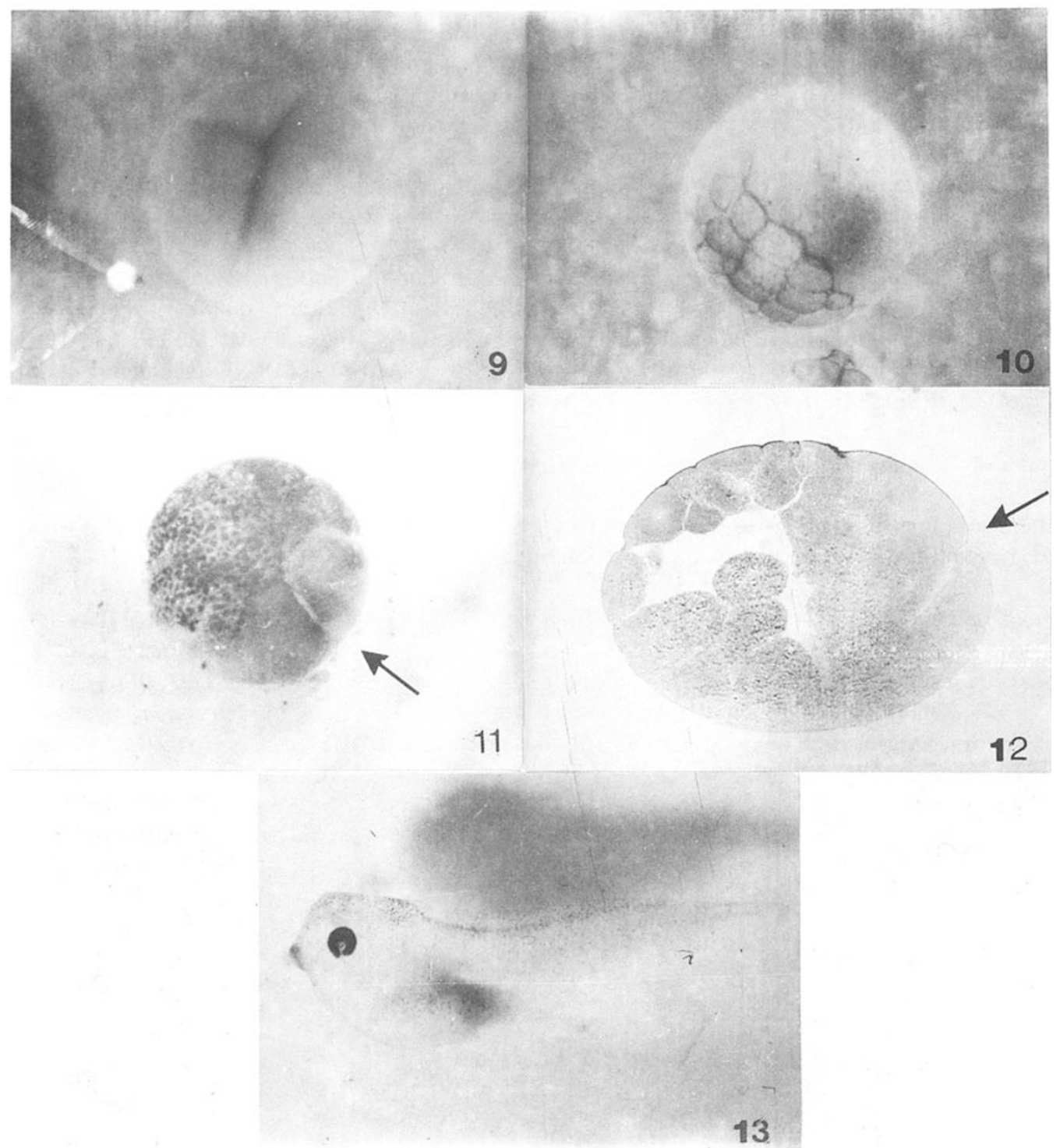

\section{Plate 2}

Only one cell of the 2-cell stage embryo was injected with antikeratin antibody(MAb AF5 IgG) in the experimental series(Group C).

Fig 9. The uninjected cell divided into two blastomeres and injected cell undivided. $\times 20$

Fig 10. About 64-celled stage in uninjected half. $\times 20$

Fig 11. Fine-cell blastula (arrow indicating injected half with only 2 blastomeres), $\times 20$

Fig 12. Section of embryo at mid-cleavage stage (arrow indicates the divisionceased AF5-injected half), $\times 30$

Fig 13. Abnormal tadpole in Group C. $\times 10$ 